\title{
Identificação sexual através do estudo anatômico do sistema urogenital em recém-eclodidos e jovens de Trachemys dorbignyi (Duméril \& Bibron) (Reptilia, Testudines, Emydidae)
}

\author{
Adriana Malvasio ${ }^{1}$ \\ Norma Gomes ${ }^{2}$ \\ Eduardo Cunha Farias ${ }^{3}$
}

\begin{abstract}
Sexual identification using anatomical study of urogenital system in hatch lings and juveniles of tracHemys dorbignyi (Duméril \& Bibron) (Reptilia, Testudines, Emydidae). Individuals of Trachemys dorbignyi (Duméril \& Bibron, 1835 ) less than 12 months old are examined for sexual identification through anatomical study of urogenital system. Histological analysis is used to confirm sexual identification. It is concluded that accurate sexual identification is possible in hatchlings using gonadal morphology. Differences between testes and ovaries are clear so histological analysis is necessary for this species only in case of doubts.

KEY WORDS. Testudines, Trachemys dorbignyi, urogenital system, sexual identification
\end{abstract}

A determinação sexual influenciada pela temperatura de incubação dos ovos ocorre em muitos Testudines, como é citado por vários autores, entre os quais: YNTEMA \& Mrosovsky (1980), em Caretta caretta Linnaeus, 1758; Miller \& LiMPUS (1981) e STANDORA \& SPOTILA (1985), em Chelonia mydas Linnaeus, 1758; AlHo et al. (1985), em Podocnemis expansa Schweigger, 1812; Silva (1986), em Lepidochelys olivacea Eschscholtz, 1829.

Provavelmente, este mecanismo de determinação sexual também ocorre em Trachemys dorbignyi Duméril \& Bibron, 1835. Estas informações são de muita importância, especialmente para os projetos de preservação de quelônios. Se a determinação do sexo é influenciada pela temperatura de incubação dos ovos, existe a possibilidade de serem devolvidos à natureza unicamente machos ou fêmeas, caso a temperatura de incubação não esteja adequada. VoGT (1994) salienta que isso muitas vezes vem ocorrendo.

Em indivíduos recém-eclodidos de Trachemys dorbignyi e aproximadamente até os dois ou três anos de idade não é possível distinguir machos e fêmeas por características externas. Por isso, um acompanhamento anatômico das gônadas torna-se fundamental para a identificação do sexo.

1) Departamento de Zoologia, Instituto de Biociências, Universidade de São Paulo. Rua do Matão, Travessa 14 321, 05508-900 São Paulo, São Paulo, Brasil.

2) Museu de Zoologia, Universidade de São Paulo. Avenida Nazaré 481, 04263-000 São Paulo, São Paulo, Brasil.

3) Instituto de Ciências Biomédicas, Universidade de São Paulo. Avenida Professor Lineu Prestes 1524, 05508-900 São Paulo, São Paulo, Brasil. 
VogT (1994), corroborando Bull \& VogT (1979) e YNTEMA (1981), salienta que o exame das gônadas em estereomicroscópio é o suficiente para identificar o sexo de recém- eclodidos em várias espécies de quelônios.

Outros autores têm trabalhado com a análise morfológica das gônadas, questionando se esta técnica, por si só, seria suficiente para a identificação do sexo dos recém- eclodidos ou se seriam necessárias preparações histológicas para sua confirmação. Como exemplo, pode ser citado o trabalho de YNTEMA \& MROSOVSKY (1980), no qual concluem que para Caretta caretta, a análise das características morfológicas das gônadas não é suficiente para identificar o sexo do indivíduo, sendo necessária a avaliação histológica. Pode também ser citado o trabalho de WHITMORE et al. (1985) com Chelonia mydas, o qual, analisando a cor e a forma das gônadas, conclui que o sexo pode ser corretamente diagnosticado na maioria dos casos.

Mediante as informações acima apresentadas, este estudo tem por objetivos a realização de um acompanhamento anatômico do sistema urogenital em jovens com idade inferior a doze meses, enfatizando as gônadas e avaliando a necessidade de observações morfológicas e histológicas para a correta identificação sexual.

\section{MATERIAL E MÉTODOS}

Todos os espécimens utilizados neste trabalho foram fornecidos pela Fundação Parque Zoológico de São Paulo e tinham idade entre vinte e dois e duzentos e noventa e quatro dias. Foram dissecados quarenta e um exemplares, todos nascidos em cativeiro.

Na tabela I, é mostrado o número de espécimens em relação ao sexo e a idade. A maior parte dos indivíduos analisados encontra-se numa faixa etária inferior a seis meses, pois nesta fase a identificação sexual é mais difícil.

Tabela I. Número total de exemplares em relação ao sexo e idade.

\begin{tabular}{lccc}
\hline Sexo & Menores de seis meses & Entre seis meses e um ano & Total \\
\hline Machos & 24 & 5 & 29 \\
Fêmeas & 9 & 3 & 12 \\
\hline Total & 33 & 8 & 41 \\
\hline
\end{tabular}

O sacrifício dos animais foi feito em câmara de éter sulfúrico. Após as tartarugas serem sacrificadas, foram tomadas quatro medidas:

Comprimento da carapaça (CCar); é medido em linha reta, na parte medial (RHODIN \& MitTERMEIER 1976), que se estende desde a borda anterior do escudo nucal, até o final da sutura entre os escudos supra caudais.

Largura máxima da carapaça (LCar); é a maior distância entre os escudos marginais de um lado a outro (CAGLE 1946).

Comprimento da sutura médio ventral do plastrão (CPla); a medida é feita a partir da sutura entre os escudos gulares, na parte mais anterior, indo até a sutura entre os escudos anais na parte mais posterior (MEDEM 1976). 
Largura do plastrão (LPla); a medida é feita seguindo a sutura entre os escudos peitorais e abdominais até o ponto onde esses dois escudos se encontram com os escudos marginais de ambos os lados.

O modo como foram tomadas as medidas, com paquímetro de precisão de $0,1 \mathrm{~mm}$, é mostrado na figura 1 . Na tabela II são observadas as medidas dos exemplares. Para a nomenclatura dos escudos córneos da carapaça e plastrão, seguiu-se Pritchard \& TREBBaU (1984).
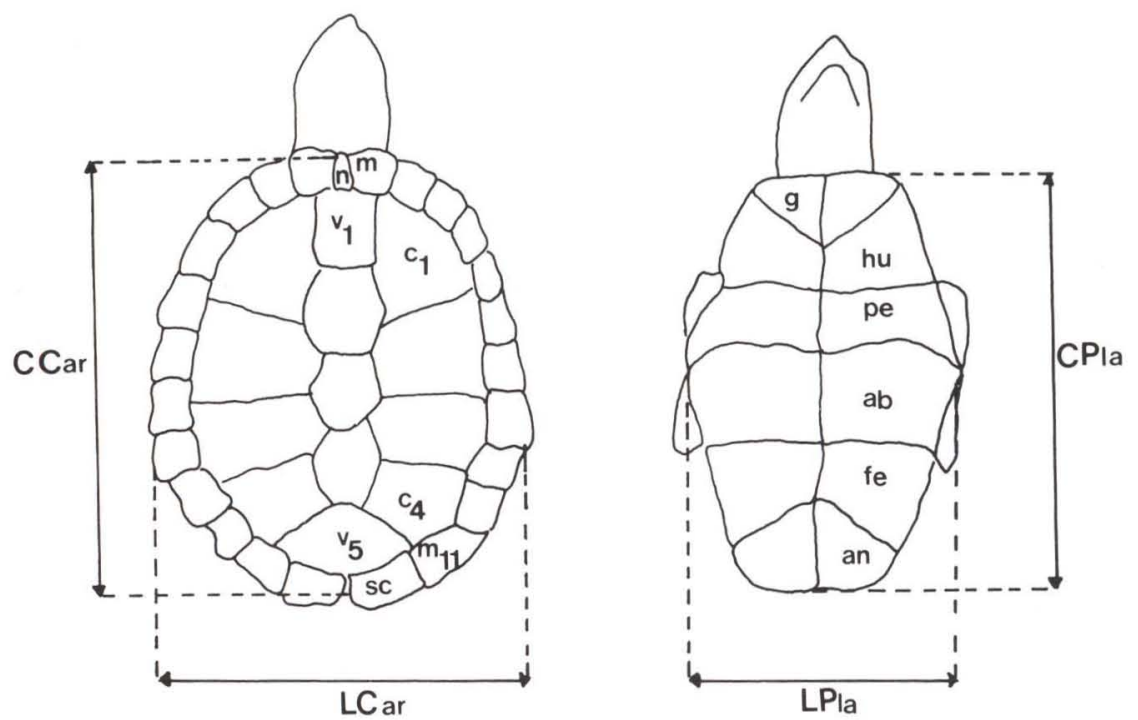

Fig. 1. Medidas utilizadas: (CCar) comprimento da carapaça, (LCar) largura máxima da carapaça, (CPla) comprimento da sutura médio ventral do plastrão, (LPla) largura do plastrão. Nomenclatura dos escudos: (ab) abdominal, (an) anal, (c) costal, (fe) femoral, (g) gular, (hu) humeral, (m) marginal, $(n)$ nucal, (pe) peitoral, (sc) supra-caudal, (v) vertebral.

Depois de tomadas as medidas, a dissecção sob estereomicroscópio era iniciada com o animal em decúbito dorsal, retirando-se o plastrão com bisturi.

A seguir, era feita uma observação geral da disposição das vísceras, depois da qual retirava-se intestino, fígado, estômago e coração, com tesoura de ponta fina. Removido o intestino, o sistema urogenital já podia ser visualizado.

A nomenclatura utilizada para o sistema urogenital baseou-se em ASHLEY (1955) e Noble \& NoBle (1940). As ilustrações mostram a vista ventral, ou seja, o plastrão voltado para o observador.

O sistema urogenital apresenta variações quanto à ausência ou presença de componentes e quanto à estrutura dos mesmos. Tais variações são melhor entendidas quando agrupam-se os indivíduos por idade. Por essa razão, para a descrição da morfologia, optou-se por dividir os exemplares em dois grupos: 1) indivíduos com menos de seis meses de idade; 2 ) indivíduos com idade entre seis meses e um ano. 
Tabela II. Relação dos exemplares utilizados no estudo, com as respectivas medidas. (M) Machos, (F) fêmeas: (CCar) comprimento da carapaça, (LCar) largura da carapaça, (CPla) comprimento do plastrão, (LPla) largura do plasträo. Os exemplares que estão no Museu de Zoologia da Universidade de São Paulo, Brasil, possuem o número MZUSP. As lâminas histológicas apresentam a mesma numeração.

\begin{tabular}{|c|c|c|c|c|c|c|}
\hline Exemplar & Sexo & $\begin{array}{l}\text { Idade } \\
\text { (dias) }\end{array}$ & $\begin{array}{l}\text { CCar } \\
(\mathrm{cm})\end{array}$ & $\begin{array}{l}\text { LCar } \\
(\mathrm{cm})\end{array}$ & $\begin{array}{l}\text { CPla } \\
(\mathrm{cm})\end{array}$ & $\begin{array}{l}\text { LPla } \\
(\mathrm{cm})\end{array}$ \\
\hline AJ1002 & M & 22 & 3,4 & 3,2 & 3,3 & 2,5 \\
\hline AJ1102 & M & 26 & 3,5 & 3,3 & 3,3 & 2,5 \\
\hline AC15024 - MZUSP 3348 & M & 29 & 3,5 & 3,2 & 3,2 & 2,4 \\
\hline AC15023 - MZUSP 3349 & M & 30 & 3,4 & 3,3 & 3,2 & 2,5 \\
\hline AC15025 - MZUSP 3350 & M & 30 & 3,5 & 3,3 & 3,4 & 2,6 \\
\hline ZO15022 - MZUSP 3351 & M & 36 & 3,5 & 3,2 & 3,3 & 2,5 \\
\hline AJ15025 - MZUSP 3344 & M & 38 & 3,5 & 3,3 & 3,3 & 2,6 \\
\hline ZP16022 - MZUSP 3353 & M & 42 & 3,4 & 3,2 & 3,1 & 2,7 \\
\hline BZ1301 - MZUSP 3355 & $\mathrm{~F}$ & 48 & 4,0 & 3,9 & 3,7 & 3,0 \\
\hline ZO15021 - MZUSP 3352 & $M$ & 50 & 3,6 & 3,3 & 3,3 & 2,5 \\
\hline BI24011 - MZUSP 3362 & M & 51 & 4,0 & 3,0 & 3,8 & 3,0 \\
\hline BZ1401 & $\mathrm{F}$ & 52 & 4,2 & 4,0 & 3,8 & 3,1 \\
\hline BI2301 - MZUSP 3363 & $M$ & 52 & 4,1 & 3,8 & 3,9 & 3,0 \\
\hline AJ15021 - MZUSP 3345 & M & 55 & 3,4 & 3,2 & 3,2 & 2,4 \\
\hline ZP16021 - MZUSP 3354 & M & 56 & 3,4 & 3,3 & 3,2 & 2,7 \\
\hline AJ15022 - MZUSP 3346 & M & 56 & 3,6 & 3,3 & 3,4 & 2,6 \\
\hline BZ16011 & $\mathrm{F}$ & 57 & 4,1 & 3,9 & 3,9 & 3,0 \\
\hline AJ15024 - MZUSP 3347 & M & 59 & 3,4 & 3,3 & 3,2 & 2,5 \\
\hline BZ17014 - MZUSP 3357 & $\mathrm{~F}$ & 63 & 3,8 & 3,6 & 3,6 & 2,9 \\
\hline BZ17013 - MZUSP 3358 & $\mathrm{~F}$ & 64 & 4,0 & 3,7 & 3,7 & 2,9 \\
\hline BZ16012 - MZUSP 3356 & $\mathrm{~F}$ & 67 & 4,0 & 3,8 & 3,8 & 3,0 \\
\hline BI24012 - MZUSP 3364 & M & 71 & 4,0 & 3,0 & 3,7 & 2,9 \\
\hline AJ15023 & M & 72 & 3,6 & 3,3 & 3,5 & 2,6 \\
\hline BZ16013 - MZUSP 3359 & $\mathrm{~F}$ & 72 & 4,0 & 3,8 & 3,7 & 2,9 \\
\hline ZO1602 & M & 77 & 3,5 & 3,3 & 3,4 & 2,6 \\
\hline BI24015 - MZUSP 3365 & $M$ & 77 & 4,2 & 3,9 & 3,8 & 3,0 \\
\hline $\mathrm{BI} 24013$ & M & 79 & 3,7 & 3,6 & 3,4 & 2,7 \\
\hline BI24014 - MZUSP 3366 & M & 79 & 4,0 & 3,8 & 3,7 & 2,9 \\
\hline BI2101 - MZUSP 3367 & M & 79 & 4,1 & 3,8 & 3,8 & 3,0 \\
\hline BZ17012 - MZUSP 3360 & $\mathrm{~F}$ & 100 & 4,0 & 3,8 & 3,7 & 3,0 \\
\hline BZ17011 - MZUSP 3361 & $\mathrm{~F}$ & 118 & 4,0 & 3,9 & 3,9 & 3,0 \\
\hline BB0103 - MZUSP 3368 & M & 131 & 3,3 & 3,2 & 3,1 & 2,5 \\
\hline BR24022 - MZUSP 3369 & M & 135 & 3,6 & 3,4 & 3,5 & 2,7 \\
\hline AR0301 - MZUSP 3370 & M & 189 & 4,1 & 4,0 & 3,9 & 3,1 \\
\hline AR07012 - MZUSP 3371 & $\mathrm{~F}$ & 190 & 4,6 & 4,2 & 4,2 & 3,2 \\
\hline JL04032 & M & 220 & 5,6 & - & 5,2 & 3,4 \\
\hline FY03012 & M & 280 & 5,3 & - & 5,1 & 3,3 \\
\hline ZI17015 - MZUSP 3373 & M & 292 & 4,0 & 3,6 & 3,7 & 2,8 \\
\hline ZI17014 - MZUSP 3374 & M & 292 & 3,8 & 3,4 & 3,5 & 2,7 \\
\hline BS18014 - MZUSP 3375 & $\mathrm{~F}$ & 293 & 6,9 & 6,2 & 6,3 & 4,7 \\
\hline BS17012 - MZUSP 3376 & $\mathrm{~F}$ & 294 & 7,5 & 7,0 & 6,7 & 5,4 \\
\hline
\end{tabular}

Quando o trabalho de observação do sistema urogenital era finalizado, os exemplares eram colocados em formalina neutra $10 \%$ para uma possível preparação histológica. 
Dos exemplares estudados, quatro foram enviados para a preparação de lâminas do sistema urogenital. Utilizaram-se duas fêmeas, uma com quarenta e oito dias e outra com sessenta e sete dias; dois machos, um com cinquenta e nove dias e outro com cento e oitenta e nove dias, cujos códigos são MZUSP 3355, MZUSP 3356, MZUSP 3347, MZUSP 3370, (Tab. II).

Como o material era bastante delicado, os rins e as gônadas não foram retirados da carapaça, exceto no exemplar MZUSP 3347. Fizeram-se cortes transversais que englobavam a própria carapaça, demandando, consequentemente, uma descalcificação antes de cortar e corar o tecido. Os cortes feitos em micrótomo foram de 8 micrômetros. A coloração foi feita com hematoxilina e eosina.

\section{RESULTADOS}

O sistema urogenital do adulto é constituído em ambos os sexos por um par de rins e ureteres, uma bexiga urinária, um par de bexigas acessórias, um seio urogenital, cloaca e aderida à face ventral de cada rim, a glândula endócrina adrenal. As estruturas sexuais no macho são um par de testículos, os canais eferentes, um par de epidídimos, um par de ductos deferentes, um pênis e podem aparecer em alguns espécimens, ovidutos remanescentes. Nas fêmeas, estas estruturas são um par de ovários, um par de ovidutos e um clitóris.

O desenvolvimento e aspecto destas estruturas, mostram variações nos grupos etários.

\section{Machos com menos de seis meses de idade}

O sistema urogenital observado nos vinte e quatro machos do grupo 1 , segue o padrão ilustrado na figura 2 e será descrito brevemente.

O sistema urogenital localiza-se imediatamente após à sutura que une a carapaça e o plastrão, comunicando-se com o exterior através da abertura cloacal.

Os rins lobados, de coloração marrom, localizam-se lateralmente à porção terminal do intestino.

A bexiga urinária transparente e vascularizada, de aspecto saculiforme, localiza-se na porção posterior dos rins, entre as bexigas acessórias, que são estruturas arredondadas, vascularizadas e brancas. Cada bexiga acessória encontrase na porção póstero-lateral do rim.

O seio urogenital, estrutura aproximadamente cilíndrica onde desembocam os ductos do sistema urinário e reprodutor, é, em muitos exemplares, praticamente imperceptível nesta faixa etária. Quando é possível observá-lo, localiza-se posteriormente aos rins e ventralmente à porção final do intestino.

A superfície ventral do rim é percorrida longitudinalmente pela veia portarenal. Medialmente à veia porta-renal, observa-se o testículo alongado, com bordas arredondadas, transparente e vascularizado e a glândula adrenal alongada, branca, com bordas irregulares e de forma grosseiramente retangular. Os testículos e as adrenais apresentam comprimento semelhante.

Em posição dorsal ao testículo, observa-se uma porção do rim modificada, de cor amarelada e com pigmentos vermelhos (provavelmente a parte mesonéfrica do rim que ainda persiste). Os testículos prendem-se a essa porção pelo mesórquio. 
Fazendo-se um corte a partir da abertura cloacal em sentido anterior, verifica-se uma estrutura alongada que se estende da abertura cloacal até a bexiga urinária. Esta estrutura apresenta uma pequena porção branca central, circundada por um tecido de cor preta, é o pênis em formação. A cloaca é uma câmara cilíndrica localizada posteriormente à bexiga urinária, com abertura transversal.
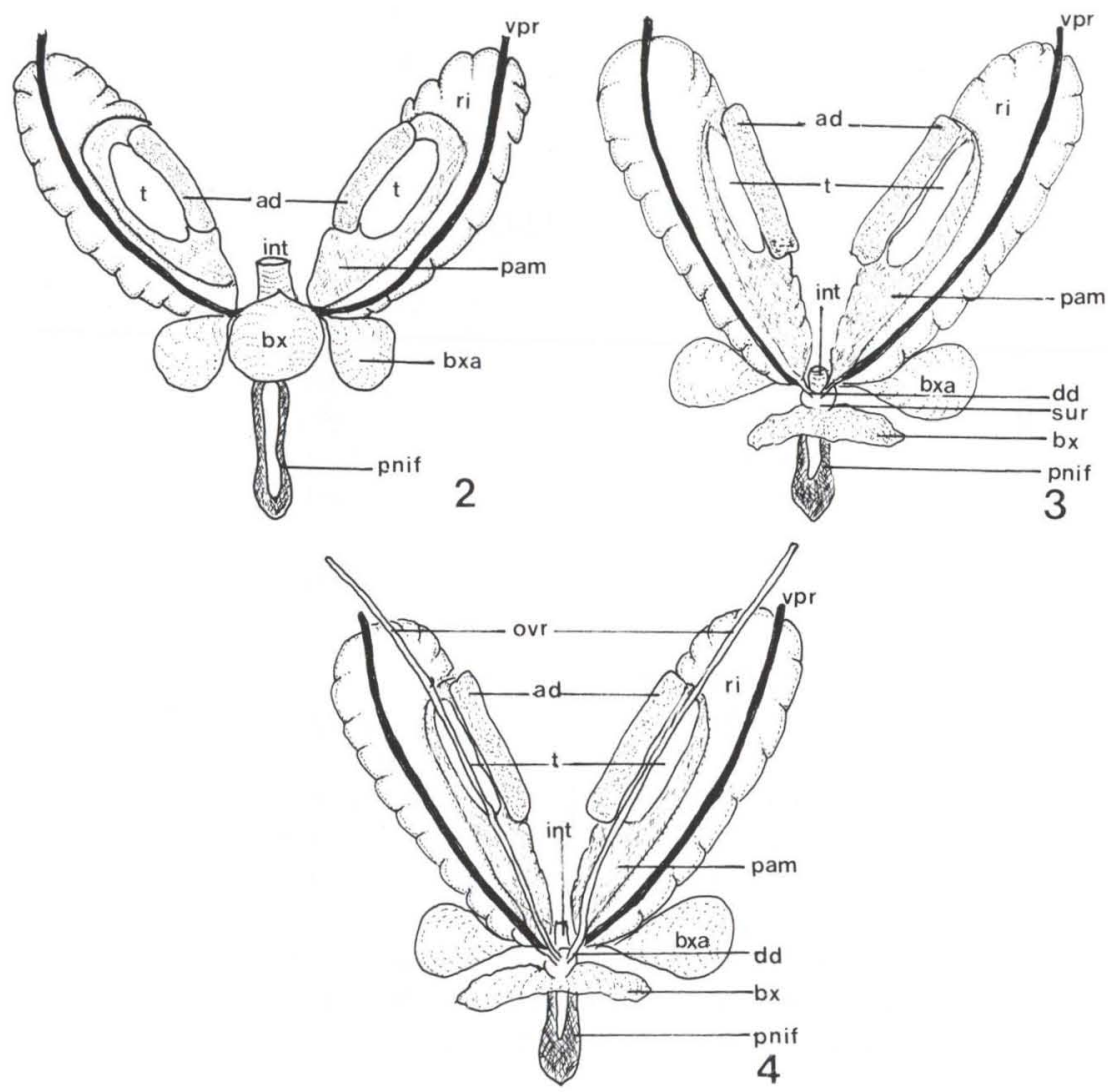

Figs 2-4. Esquema do sistema urogenital de machos. (2) menores de seis meses; (3) entre seis meses e um ano; (4) MZUSP 3370 (Tab. II). (ad) Adrenal, (bx) bexiga urinária, (bxa) bexiga acessória, (dd) ducto deferente, (int) intestino, (ovr) oviduto remanescente, (pam) porção amarela, (pnif) pênis em formação, (t) testículo, (vpr) veia porta-renal.

\section{Machos entre seis meses e um ano}

Cinco exemplares foram observados neste grupo, cuja disposição das estruturas do sistema urogenital está representada na figura 3.

A porção amarela dos rins, dorsal aos testículos, persiste, sendo possível observar-se na sua parte posterior, que termina no seio urogenital, um ducto, provavelmente o ducto deferente. 
Observa-se claramente nesta fase o seio urogenital, localizado posteriormente aos rins e ventralmente à porção final do intestino. Pode-se descrevê-lo como uma estrutura esbranquiçada de forma aproximadamente cilíndrica.

Dentre os cinco machos, foi notada a presença de ovidutos remanescentes em um, com idade de seis meses e nove dias. A figura 4 ilustra esse exemplar.

\section{Fêmeas com menos de seis meses de idade}

O sistema urogenital observado nas nove fêmeas do grupo 1 , segue o padrão descrito a seguir, ilustrado na figura 5 .
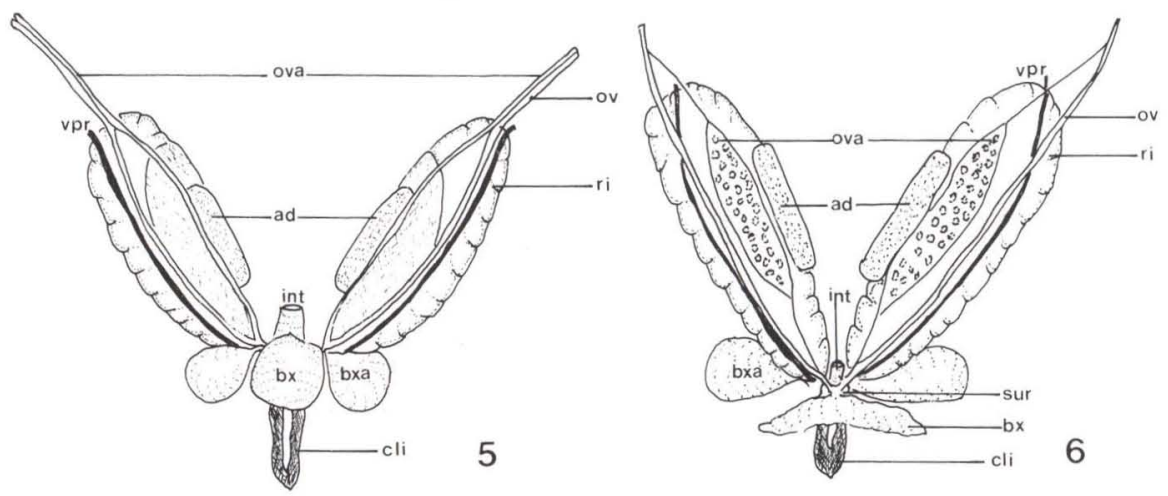

Figs 5-6. Esquema do sistema urogenital de fêmeas. (5) menores de seis meses; (6) entre seis meses e um ano. (ad) adrenal, (bx) bexiga urinária, (bxa) bexiga acessória, (cli) clitóris (em formação), (int) intestino, (ov) oviduto, (ova) ovário, (sur) seio urogenital, (vpr) veia porta-renal.

Como nos machos, o sistema urogenital das fêmeas localiza-se logo após a sutura que une a carapaça e o plastrão, comunicando-se com o exterior através da abertura cloacal.

Os rins têm o mesmo aspecto lobado e coloração marrom, como observado nos machos, mas não apresentam a porção amarela tão evidente. Os rins são percorridos longitudinalmente, na parte ventral, pela veia porta-renal.

Quanto à forma e localização, a bexiga urinária e as bexigas acessórias apresentam o mesmo padrão observado nos machos.

O seio urogenital, do mesmo modo que nos machos, apresenta-se, na maioria dos exemplares desta faixa etária, bastante indefinido. Quando é possível distinguílo, apresenta-se de forma aproximadamente cilíndrica e na mesma localização dos machos.

Os ovidutos, ovários e glândulas adrenais também se encontram na superfície ventral dos rins, medialmente à veia porta-renal, nesta mesma ordem. O ovário e o oviduto têm aspectos semelhantes, sendo cilíndricos, alongados e transparentes, ultrapassando a extensão dos rins em ambas extremidades. O ovário tem diâmetro um pouco maior do que o oviduto. O ovário está preso ao rim pelo mesovário.

Afastando ovário e oviduto, observa-se uma membrana transparente que parece ser uma continuação do mesovário. Dorsalmente a essa membrana, fica a porção amarela diferenciada dos rins. 
Fazendo um corte longitudinal da abertura cloacal em sentido anterior e retirando-se a cintura pélvica, observa-se o clitóris em formação, como uma estrutura alongada e formada predominantemente por um tecido de côr preta. Essa estrutura estende-se da abertura cloacal até a bexiga urinária e é semelhante ao pênis dos machos do mesmo grupo etário.

A glândula adrenal apresenta-se da mesma forma que nos machos do mesmo grupo etário.

\section{Fêmeas entre seis meses e um ano}

Neste grupo, os três exemplares estudados são ilustrados pela figura 6, apresentando modificações em relação ao grupo 1.

As três fêmeas já não apresentam mais a porção amarela dos rins. Os ovários encontram-se mais diferenciados do que os do grupo anterior, sendo bem mais espessos do que os ovidutos e apresentando aspecto granuloso, pela presença de inúmeros óvulos pequenos e arredondados.

Os ovidutos terminam no seio urogenital, que agora já pode ser claramente percebido. A localização e a descrição do seio urogenital seguem o mesmo padrão dos machos desta faixa etária.

\section{Histologia do sistema urogenital}

Machos. A histologia do exemplar MZUSP 3370 (Tab. II), representada nas fotografias das figuras 7-8, mostra, além do testículo, a presença do oviduto remanescente.
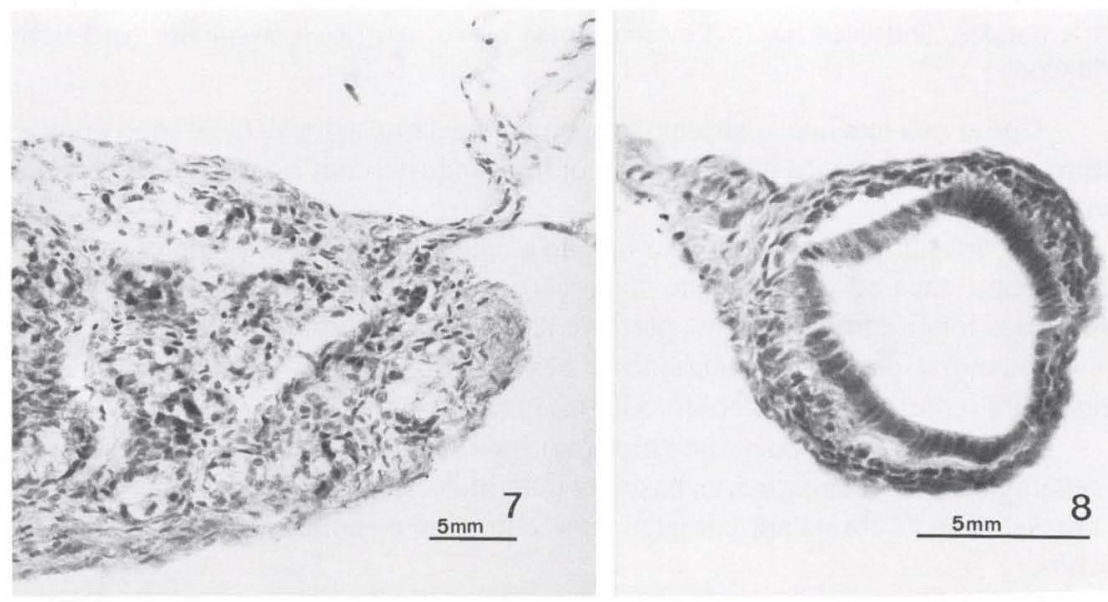

Figs 7-8. (7) Corte histológico do testículo; (8) corte histológico do oviduto remanescente. O exemplar utilizado é o MZUSP 3370 (Tab. II).

O testículo é recoberto por epitélio pavimentoso simples, pouco diferenciado. Sua caracterização histológica decorre da presença de cordões de células vacuolizadas, que serão futuros túbulos seminíferos.

O oviduto remanescente apresenta-se pouco diferenciado, sendo constituído por epitélio prismático simples, apoiado sobre tecido de aspecto mesenquimal. 
Fêmeas. As fotografias das figuras 9-10 mostram a histologia do exemplar MZUSP 3356 (Tab. II), cujos ovários estão pouco diferenciados, sendo histologicamente caracterizados pela presença de folículos ovarianos que aparecem como áreas ovaladas de aspecto vacuolizado, circundadas por células foliculares.

O oviduto, pouco diferenciado, é constituído por um epitélio prismático simples, apoiado em fina camada de tecido com características mesenquimais.
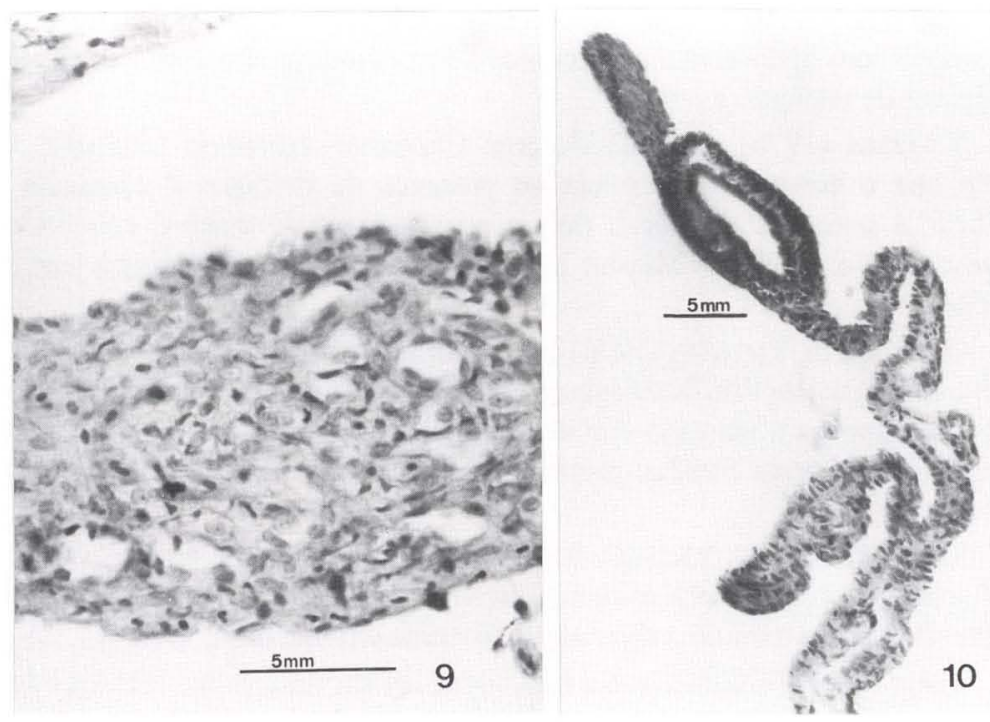

Figs 9-10. (9) Corte histológico do ovário; (10) corte histológico do oviduto. O exemplar utilizado é o MZUSP 3356 (Tab. II).

\section{DISCUSSÃO}

\section{Identificação do sexo em recém-eclodidos}

Foram dissecados trinta e três exemplares menores do que seis meses, sendo vinte e quatro machos e nove fêmeas. Dezoito deles apresentavam idade inferior a sessenta dias (Tab. I). Após o estudo anatômico do sistema urogenital, pode-se dizer que é possível identificar o sexo em recém eclodidos de Trachemys dorbignyi. As diferenças observadas entre machos e fêmeas, especificamente entre os testículos de forma ovalada e os ovários, estruturas bastante alongadas e finas, podem ser verificadas nas figuras 2 (machos) e 5 (fêmeas).

A análise histológica não é necessária para identificar o sexo de Trachemys dorbignyi, a não ser que surjam casos duvidosos. Apesar de um macho de seis meses e nove dias ter apresentado ovidutos remanescentes, a gônada não deixava dúvidas de ser um testículo, o que foi confirmado histologicamente. Portanto, os ovidutos remanescentes, neste caso, não interferiram na diferenciação das gônadas, pois 
nenhuma delas, no representante analisado, apresentou macroscopicamente ou microscopicamente características de testículos e ovários ao mesmo tempo.

Estes resultados são semelhantes aos encontrados por DANNI \& ALHO (1985), que apontam uma diferenciação sexual nítida, em representantes recém eclodidos de Podocnemis expansa, identificada na maioria dos casos, pela simples dissecção. Eles encontraram ovidutos remanescentes numa pequena porcentagem do material examinado. Em um macho com ovidutos remanescentes, observaram uma gônada com aparência macroscópica de testículo, porém com características histológicas de testículo e ovário.

YNTEMA (1976), trabalhando com Chelydra serpentina Linnaeus, 1758, conclue que o critério de ausência ou presença de ovidutos é adequado para identificar o sexo desta espécie, pois a porcentagem de machos com ovidutos remanescentes é pequena. Mesmo assim, o autor indica a histologia em casos duvidosos.

O critério de YNTEMA (1976) é corroborado por DANNI \& ALHO (1985), em Podocnemis expansa. Em Trachemys dorbignyi, este tipo de identificação sexual é possível, pois só foi observado um macho com ovidutos remanescentes. Em nossa opinião, a comparação entre as próprias gônadas, é mais fácil e precisa para esta espécie.

Em contrapartida, YNTEMA \& MROSOVSKY (1980) concluem ser necessária a avaliação histológica para a identificação sexual em Caretta caretta, pois as gônadas não apresentam uma diferenciação nítida em machos e fềmeas.

VoGT (1994), salienta que a histologia, apesar de ser uma técnica bastante adequada para sexar as gônadas, só deve ser usada em casos de dúvida da identificação sexual, pois é mais trabalhosa e mais cara do que o exame em estereomicroscópio.

Também é comentado por VoGT (1994), que a laparoscopia é uma técnica que pode ser utilizada sem sacrificar o animal, porém, os espécimens devem ter um maior porte e o equipamento muitas vezes é de difícil acesso, sendo estes fatores, limitantes.

O método proposto por VAN DER HEIDEN et al. (1985), para tartarugas marinhas, de clareamento das gônadas em glicerina, não é adequado a todas as espécies e circunstâncias, conforme mencionado por MROSOVSKY \& GODFREY (1995)

Para Trachemys dorbignyi, vale ressaltar novamente que a identificação sexual através do estudo das gônadas sob estéreomicroscópio é suficiente, usando-se a análise histológica apenas em casos duvidosos. Também acreditamos que a identificação sexual através de dissecção é o método mais simples, rápido e com custo mais baixo, quando características externas não permitem a diferenciação.

O pênis e o clitóris em recém eclodidos apresentam-se ainda em formação e são bastante semelhantes em estrutura, não podendo ser usados para identificação sexual, o mesmo ocorrendo em Geochelone carbonaria. RISLEY (1933) chega à conclusão que para Sternotherus odoratus Latreille, 1802, o clitóris apresenta-se menor do que o pênis, mesmo em recém eclodidos, porém ressalta que ocorre uma 
grande variação nessa estrutura e em suas proximidades. Sendo assim, o caráter não é confiável para sexar os exemplares nesse estágio de desenvolvimento.

\begin{abstract}
AGRADECIMENTOS. Ao diretor da Fundação Parque Zoológico de São Paulo, Dr. Adayr Mafuz Saliba, ao chefe do Setor de Répteis, Mario Borges da Rocha e ao Dr. Flavio de Barros Molina, pelo fornecimento do material e apoio recebido. Ao Dr. Flavio de Barros Molina, agradecemos também pela leitura, sugestões ao manuscrito e pelas comunicações pessoais. Ao diretor do Museu de Zoologia da Universidade de São Paulo, Dr. José Luís M. Leme, pelo uso das instalações e aos demais funcionários, pelo apoio recebido. À Maria Tereza Osório Mallmann, pelas comunicações pessoais. À CAPES, pela Bolsa de Mestrado concedida à Adriana Malvasio.
\end{abstract}

\title{
REFERÊNCIAS BIBLIOGRÁFICAS
}

AlHO, C.J.R.; T.M.S. DANNI \& L.F.M. PÁDUA. 1985. Temperature-dependent Sex Determination in Podocnemis expansa (Testudinata: Pelomedusidae). Biotropica 17 (1): 75-78.

ASHLEY, L.M. 1955. Laboratory Anatomy of the Turtle. Iowa, WM. C. Brown Company. $48 \mathrm{p}$.

Bull, J.J. \& R.C. VogT. 1979. Temperature-dependent Sex Determination in Turtles. Science 206: 1186-1188.

Cagle, F.R. 1946. The Growth of the Slider Turtle, Pseudemys scripta elegans. Amer. Midland Nat. 36: 685-729.

DANnI, T.M.S. \& C.J.R. AlHo. 1985. Estudo Histológico da Diferenciação Sexual em Tartarugas Recém-Eclodidas (Podocnemis expansa, Pelomedusidae). Rev. Brasil. Biol. 45 (3): 365-368.

MEDEM, F. 1976. Recomendaciones Respecto a Contar el Escamado y Tomar las Dimensiones de Nidos, Huevos y Ejemplares de los Crocodylia y Testudines. Lozania 20: 1-17.

MiLLER, J.D. \& C.J. LimPUS. 1981. Incubation period and sexual differentiation in the green turtle Chelonia mydas L. Melburne Herpetological Symposioum, Victoria, 1980, p. 66-73. In: C.B. BANKS \& A.A. MARTIN (Ed.). Proceedings of Melburne Herpetological Symposioum, Victoria.

Mrosovsky, N. \& M.H. Godfrey. 1995. Manipulating Sex Ratios: Turtles Speed Ahead! Chelonian Conservation and Biology 1 (3): 238-240.

NoBle, G.A. \& E.R. NoBle. 1940. A brief anatomy of the turtle. California, Standford University Press. 46p.

Pritchard, P.C.H. \& P. TRebBaU. 1984. The Turtles of Venezuela. Caracas, Society for the Study of Amphibians and Reptiles, 403p.

Risley, P.L. 1933. Contributions on the Development of the Reproductive System in the Musk Turtle, Sternotherus odoratus (Latreille). II. Gonadogenesis and Sex Differentiation. Zeitschrift für Zellforschung und mikroskopische Anatomie 18: 493-543.

Rhodin, A.G.J. \& R.A. MitTermeIER. 1976. Chelodina parkeri, A New Species of Chelid Turtle from New Guinea, with a Discussion of Chelodina siebenrocki Werner, 1901. Bull. Mus. Comp. Zool., Harvard, 147 (11): 465-488. 
Silva, F. DE A. 1986. La Temperatura Como Factor Determinante de Diferenciación sexual en Lepidochelys olivacea (Tortuga Golfina). Tiempos de Ciência 2: 17-20.

Standora, E.A. \& J.R. Spotila. 1985. Temperature Dependent Sex Determination in Sea Turtles. Copeia 1985 (3): 711-722.

van DER Heiden, A.M.; R. BRiseÑo-DueÑas \& D. Rios-Olmeda. 1985. A Simplified Method for Determination Sex in Hatchling Sea Turtles. Copeia 1985 (3): 779-782.

VogT, R.C. 1994. Temperature Controlled Sex Determination as a Tool for Turtle Conversation. Chelonian Conservation and Biology 1 (2): 159-162.

Whitmore, C; P. Dutton \& M. Mrosovsky. 1985. Sexing of Hatching Sea Turtles: Gross Appearance Versus Histology. Jour. Herpetol. 19 (3): 430-431.

YNTEMA, C.L. 1976. Effects of Incubation Temperatures on Sexual Differentiation in the Turtle, Chelydra serpentina. Jour. Morphol. 150: 453-462.

- 1981. Characteristics of Gonads and Oviducts in Hatchlings and Young of Chelydra serpentina Resulting from Three Incubation Temperatures. Jour. Morphol. 167: 297-304.

YNTEMA, C.L. \& N. Mrosovsky. 1980. Sexual Differentiation in Loggerheads (Caretta caretta) Incubated at Different Controlled Temperatures. Herpetologica 36 (1): 33-36.

Recebido em 27.VI.1997; aceito em 25.I.1999. 